\title{
O conceito de inconsciente para Vigotski: primeiras aproximações
}

\author{
Elis Bertozzi Aita, (D) * Silvana Calvo Tuleski (iD \\ Universidade Estadual de Maringá, Maringá, PR, Brasil
}

\begin{abstract}
Resumo
Objetivou-se compreender, a partir da Psicologia Histórico-Cultural, o conceito de inconsciente para Vigotski. Foi realizado um estudo conceitual, sistematizando o que este autor elaborou sobre o inconsciente. Vigotski entende que o conceito de inconsciente, juntamente com os conceitos de psique e consciência, é um dos principais problemas metodológicos da Psicologia. Para este autor, os conteúdos não conscientizados são uma tendência da atividade da própria consciência, e radicam das relações sociais, da produção da vida material. Ao longo da ontogênese, desde o nascimento até a morte, o ser humano, por meio das apropriações dos instrumentos materiais e simbólicos de sua cultura, reorganiza seu psiquismo em graus mais complexos. O que baliza o alcance deste desenvolvimento não são as condições puramente biológicas, mas as mediações dadas na concretude da vida singular. Nesse processo, para um pleno desenvolvimento é imprescindivel que o homem submeta as relações sociais objetivadas ao seu controle coletivo consciente, para que possa se desenvolver como individualidade livre e universal.
\end{abstract}

Palavras-chave: Vigotski; consciência; inconsciente.

\section{Vigotski's concept of unconscious: first aproaches}

\begin{abstract}
The objective was to understand, based on Historical-Cultural Psychology, the concept of unconscious for Vigotski. A conceptual study was carried out, systematizing what this author elaborated on the unconscious. Vigotski understands that the concept of the unconscious, together with the concepts of psyche and consciousness, is one of the main methodological problems of Psychology. For this author, the unconscious contents are a tendency of the activity of the conscience itself, and are rooted in social relations, in the production of material life. Throughout ontogenesis, from birth to death, the human being, through the appropriations of material and symbolic instruments of his culture, reorganizes his psyche in more complex degrees. What characterizes this scope of this development is not the purely biological conditions, but the mediations given in the concreteness of the singular life. In this process, for a full development it is essential that man submits the objectified social relations to his conscious collective control, so that he can develop as a free and universal individuality.
\end{abstract}

Keywords: Vigotski; consciousness; unconscious.

\section{El concepto de inconsciente para Vygotski: primeras aproximaciones}

\section{Resumen}

El objetivo fue comprender, desde la Psicología Histórico-Cultural, el concepto de inconsciente para Vigotski. Se realizó un estudio conceptual, sistematizando lo que este autor elaboró sobre el inconsciente. Vigotski entiende que el concepto de inconsciente, junto con los conceptos de psique y conciencia, es uno de los principales problemas metodológicos de la Psicología. Para este autor, los contenidos no conscientes son una tendencia de la actividad de la propia conciencia, y están enraizados en las relaciones sociales, en la producción de vida material. A lo largo de la ontogénesis, desde el nacimiento hasta la muerte, los seres humanos, mediante la apropiación de instrumentos materiales y simbólicos de su cultura, reorganizan su psique en grados más complejos. Lo que marca el alcance de este desarrollo no son las condiciones puramente biológicas, sino las mediaciones dadas en la concreción de la vida singular. En este proceso, para un pleno desarrollo, es fundamental que el hombre someta las relaciones sociales objetivadas a su control colectivo consciente, para que pueda desarrollarse como una individualidad libre y universal.

Palabras clave: Vigotski; conciencia; inconsciente.

No presente artigo tivemos como objetivo compreender, a partir da Psicologia Histórico-Cultural e do Materialismo Histórico-Dialético, como Lev Semionovitch Vigotski (1896-1934) entendia o conceito de inconsciente. Para tanto, buscamos realizar uma análise teórica conceitual, sistematizando o que Vigotski elaborou sobre tal conceito. Realizamos um estudo teórico-metodológico e conceitual de cunho bibliográfico a respeito do termo vigotskiano de inconsciente, a partir dos textos produzidos pelo autor aos quais tivemos acesso. Toman-

\footnotetext{
^Endereço para correspondência: Universidade Estadual de Maringá, Centro de Ciências Humanas Letras e Artes, Departamento de Psicologia. Av. Colombo, 5790, zona 7, Maringá, PR - Brasil. CEP: 87020-900

Emails: elis aita@outlook.com, silvanatuleski@gmail.com

Os dados completos das autoras encontram-se ao final do artigo.
}

do como base o método dialético, buscamos estudar os textos de Vigotski como um todo, ou seja, compreender cada texto em particular relacionando-o com o conjunto da obra deste autor, porque o pensamento de um autor se constitui como uma totalidade. Além disso, buscamos ler essa produção por ordem cronológica, visando perceber o movimento de sistematização do conceito que elas apresentam. Analisamos também as relações históricas e políticas que estão imbricadas com a construção da psicologia soviética, procurando compreender em que contexto a Psicologia Histórico-Cultural foi construída, com qual objetivo e para atender a que necessidades materiais. 
No Brasil as contribuições da teoria vigotskiana têm sido exploradas principalmente no campo da educação, desde a difusão dos textos deste autor, no início da década de 1980. É na área escolar que são amplamente estudadas suas análises acerca do desenvolvimento do psiquismo e do papel da aprendizagem neste processo. Apesar da difusão da teoria de Vigotski e, posteriormente, dos demais autores da Psicologia Histórico-Cultural na Psicologia, ainda são poucos os estudos desta corrente teórica no que diz respeito à psicologia clínica, por exemplo. Os estudos sobre o desenvolvimento da personalidade, como o empreendido por Martins (2007), sobre as emoções, com destaque para os trabalhos de Toassa (2009) e sobre a psicopatologia, com ênfase para Silva (2014), por exemplo, são fundamentais para que possamos construir um aporte teórico-metodológico para o trabalho clínico com crianças, adolescentes e adultos, a partir da Psicologia Histórico-Cultural.

Um dos temas fundamentais relacionado com a psicologia clínica diz respeito ao "inconsciente". Os processos inconscientes são pouco discutidos a partir da Psicologia Histórico-Cultural. Diante disso, compreendemos que é fundamental abordarmos este assunto e construirmos um arcabouço teórico do que são e como se constituem os processos inconscientes, para que possamos explicar o psiquismo humano em todos os seus aspectos e delinear o trabalho clínico, suas possibilidades e objetivos.

Para mapear o estado da arte sobre o conceito de inconsciente nos estudos dos autores da Psicologia Histórico-Cultural, fizemos um levantamento no banco de dados SciELO a partir da palavra-chave "inconsciente" somada a uma das seguintes: "Vigotski" (buscou-se pelas diversas variações da grafia do nome deste autor); "Psicologia Histórico-Cultural"; "Psicologia Sócio-Histórica". A pesquisa foi realizada em todos os artigos disponíveis no SciELO, independentemente do ano de sua publicação.

Nessa pesquisa encontramos dois artigos que discutem o tema, ambos de autoria de Santos e Leão (2012, 2014). Este pequeno número de artigos publicados demonstra que o tema ainda é pouco estudado a partir dessa abordagem. Santos e Leão (2012) também apontam a necessidade e a importância do aprofundamento dos estudos a respeito do inconsciente a partir da Psicologia Sócio-Histórica.

O próprio Vigotski (2004a) destaca que os conceitos de "psique", "consciência" e "inconsciente", mais do que temas fundamentais para a Psicologia, são aspectos que dizem respeito aos princípios de estruturação desta ciência. Os diversos sistemas psicológicos existentes se desenvolveram de maneiras distintas ao tentarem explicar estes três termos, o que demonstra o valor metodológico que eles possuem para qualquer corrente psicológica. Diante disso, o autor aponta a importância da análise metodológica sobre o que se tem produzido historicamente a respeito desses três objetos. Apesar disso, verificamos que Vigotski não se dedicou em particular ao estudo do inconsciente ao longo de sua obra, porém entendemos que a sistematiza-

Fractal, Rev. Psicol., v. 33 - n. 2, p. 62-71, 2021 ção deste conceito faz-se necessária, visto que o próprio autor o considera como um dos principais problemas metodológicos da Psicologia (VIGOTSKI, 2004a).

Vigotski se dedicou ao estudo do desenvolvimento histórico do psiquismo humano. Conforme foi discutindo o conceito de consciência, ele também se debruçou, de forma indireta, sobre o estudo do inconsciente. $\mathrm{O}$ autor não escreveu um texto dedicando-se exclusivamente ao estudo dos fenômenos inconscientes do psiquismo humano; porém, ao dedicar-se ao estudo do desenvolvimento da consciência humana e das funções psicológicas superiores, nos dá condições para pensar o que seriam os fenômenos que ficam alheios à consciência. Ao fazer isso, Vigotski perpassou o tema do inconsciente em diversos trabalhos.

Entendemos que a análise e a compreensão dos processos psíquicos inconscientes contribuem para o trabalho do psicólogo - de forma geral, porque possibilitam compreender o psiquismo humano em sua totalidade, e de forma específica, para o trabalho do psicólogo clínico, já que um entendimento mais completo a respeito do inconsciente possibilita o planejamento do trabalho a ser realizado, de seus objetivos e dos meios pelos quais estes objetivos podem ser alcançados. Pretendemos que nosso trabalho, ainda que inicial, contribua para a construção de um corpo teórico que discuta a atuação clínica do psicólogo a partir da Psicologia Histórico-Cultural e, mais do que isso, que contribua para a ciência psicológica, já que a compreensão da dimensão inconsciente do comportamento humano interessa à Psicologia como um todo.

É fundamental destacarmos que é um estudo inicial sobre o conceito de inconsciente em Vigotski e que não pretende, de forma alguma, esgotar a questão ou se apresentar como uma concepção construída definitivamente. Objetivamos, na verdade, ampliar o debate já iniciado preliminarmente por alguns autores contemporâneos, apresentando nossas análises sobre o que Vigotski formula a respeito do tema, para que os leitores e demais pesquisadores da Psicologia Histórico-Cultural possam dialogar conosco, apontar os avanços e limites das nossas considerações e dar continuidade ao estudo aqui empreendido.

\section{$O$ conceito de inconsciente nos trabalhos iniciais de Vigotski}

No texto Psicologia da Arte, Vigotski (1972) discute sobre as obras de arte e seu significado histórico. Para o autor, na psicologia da arte, a respeito do conceito de inconsciente, ocorre o mesmo que na Psicologia de forma geral. Para a psicologia tradicional o inconsciente é algo oculto que, por sua própria natureza, não podemos compreender. Vigotski (1972, p. 100) assinala este ponto de vista como errôneo, porque a ciência não estuda apenas o que é imediatamente acessível à consciência ou à observação, mas também estuda fenômenos de forma indireta, por meio de indícios e vestígios:

[...] De igual modo o inconsciente se torna objeto de estudo do psicólogo não por si mesmo, mas indiretamente, através da análise dos vestígios que deixa no nosso psiquismo. Não existe um muro intransitável entre a consciência e o inconsciente. Os processos que começam no inconsciente emergem frequentemente à consciência e, ao contrário, 
deslocamos para a esfera do inconsciente numerosos fenômenos conscientes. Existe uma relação dinâmica, viva, permanente, que não se interrompe nem por um instante, entre ambas as esferas de nossa vida psíquica. $\mathrm{O}$ inconsciente influencia os nossos atos, manifesta-se no nosso comportamento, e por esses vestígios e manifestações aprendemos a identificar o inconsciente e as leis que o regem.

O que podemos concluir a partir deste texto de Vigotski é que é legitimo o estudo dos processos inconscientes, já que a psicologia não deve apenas estudar o que está acessível à observação direta, até porque nem todos os fenômenos da própria consciência são acessíveis à observação. $\mathrm{O}$ inconsciente pode ser apreendido pelos vestígios que deixa em nosso psiquismo. Vigotski deixa claro que, para compreendermos a totalidade do psiquismo humano e das vivências humanas, é preciso considerarmos também os processos inconscientes, porque eles fazem parte deste psiquismo. $\mathrm{O}$ inconsciente influencia o comportamento do sujeito e só poderemos compreender este comportamento de forma mais abrangente se compreendermos o inconsciente e as leis que o regem em relação com a consciência e suas leis.

Outro ponto importante discutido por Vigotski nesse texto é que não existe uma barreira intransponível que separe os conteúdos conscientes dos conteúdos inconscientes. Existe uma relação dinâmica entre estas esferas, na qual conteúdos inconscientes podem tornar-se conscientes e vivências conscientes podem ser deslocadas para o inconsciente; ou seja, todos os conteúdos são potencialmente conscientes.

Já no texto "O significado histórico da crise da psicologia" Vigotski (2004b) expõe que o problema do inconsciente é um problema metodológico, e só pode ser resolvido pela ciência geral. As análises sobre os aspectos parciais da vida inconsciente devem ser precedidas de uma análise geral, que incluiria este conceito no sistema de conceitos da psicologia e determinaria o caminho metodológico para a análise do inconsciente. Continuando esta discussão, Vigotski observa que a própria terminologia que utilizamos para nominar o fenômeno (subconsciente, inconsciente ou superconsciente) já traz consigo a base teórica que elegemos para discutir o assunto.

Vigotski (2004a) defende a análise metodológica do problema do inconsciente e postula como principal questão compreender se o mesmo é psíquico ou fisiológico. Defende um enfoque dialético da questão da "psique", "consciência" e "inconsciente", partindo da unidade dos processos psíquicos e fisiológicos e analisando a totalidade do fenômeno, o que implica considerar tanto seus aspectos subjetivos quanto os objetivos. Estudá-los de forma separada é torná-los totalmente incompreensíveis (isto não significa considerá-los como idênticos: defende-se uma unidade, e não uma identidade destes fenômenos). A psique não é algo imaterial, ela surgiu em um processo de desenvolvimento e está ligada diretamente às funções organizadas de nosso cérebro. Assim, o objeto de estudo da psicologia dialética é o processo psicofisiológico integral do comportamento, que une dialeticamente - e não mecanicamente - processos psíquicos e fisiológicos.
Para Vigotski (2004a), a psicologia foi forçada a introduzir o conceito de inconsciente, pois se via obrigada a explicar situações nas quais o indivíduo considerava saber a causa do que fazia, quando na realidade o motivo de suas ações era outro; ou seja, o sujeito age conscientemente, mas não tem consciência do motivo pelo qual age. Além disso, a psicologia se viu diante do fato de que a própria consciência dos fenômenos pode se dar em diferentes graus. Podemos viver algo de forma mais consciente e clara, ou menos consciente. Existem conteúdos que entram e saem de nossa consciência. De algumas coisas temos apenas uma impressão vaga, e existem também impressões vivas ligadas a nosso sistema real de vivências, como os sonhos. Diante desses fatos, os autores passaram a compreender que um fenômeno não se transforma em menos psíquico por ser menos consciente.

Vigotski (2004a) destaca que a psicologia dialética analisa este problema de forma distinta, pois rompe com este dualismo que considera o inconsciente como algo psíquico ou fisiológico. Esclarece Vigotski (2004a, p. 156):

Para nós é importante formular a pergunta assim: é psicológico o inconsciente e pode ser considerado dentro de outros fenômenos homogêneos como mais um aspecto dos processos de comportamento junto com os processos psicológicos a que nos referimos antes? Também a essa pergunta já respondemos acima ao analisarmos a psique e afirmávamos que é preciso considerar esta [a psique] como parte integrante de um processo complexo que não se limita em absoluto a sua vertente consciente; por isso, consideramos que na psicologia é completamente lícito falar do psicologicamente consciente e inconsciente: o inconsciente é potencialmente consciente (grifo nosso).

O inconsciente é psicofisiológico, como são psicofísicas todas as funções elementares e superiores, a personalidade e a própria consciência. Cumpre lembrar que neste texto Vigotski usa o termo psicológico como correspondente de psicofisiológico, referindo-se à atuação conjunta e imbricada dos processos psíquicos e físicos. Vigotski delineia neste trecho um entendimento importante: para ele, os processos inconscientes são potencialmente conscientes. Em nossa análise, isto quer dizer que não existe uma instância psíquica inconsciente, totalmente separada da consciência. Os processos inconscientes são potencialmente conscientes, ou seja, podem ser conscientizados.

\section{A dinâmica consciente/inconsciente e o desenvolvimento das funções psicológicas superiores}

No texto "História do desenvolvimento das funções psicológicas superiores", Vigotski (2000) deixa claro que a compreensão de como se desenvolvem as funções psíquicas é fundamental para que possamos compreender o desenvolvimento da personalidade do indivíduo. $\mathrm{O}$ que diferencia as funções psíquicas elementares das superiores é que estas últimas têm origem cultural, pois se formaram ao longo do desenvolvimento histórico dos homens. É a partir da cultura que o homem constrói sua personalidade, mediante o processo de apropriação dos conhecimentos construídos historicamente, desenvol- 
vendo, assim, suas funções superiores, como o raciocínio lógico, o pensamento abstrato, a capacidade de planejamento e outras funções.

Isto significa que toda função psicológica superior aparece em dois planos, sendo primeiramente interpsíquica, presente nas atividades coletivas e sociais, para depois tornar-se intrapsíquica, como propriedade interna do psiquismo. Toda função superior foi antes externa, social, para depois tornar-se interna (VIGOTSKI, 2000).

Vigotski (2000) compreende que a criança aplica a si mesma as formas de comportamento que os outros aplicavam a ela, ou seja, ela assimila as formas sociais da conduta e as transfere para si. Os signos são inicialmente um meio de relação social, para posteriormente transformarem-se em um meio de influência do sujeito sobre si mesmo. Em outras palavras, o sujeito se relaciona consigo mesmo da mesma forma como as pessoas se relacionam com ele, assim como o pensamento verbal é a internalização da linguagem. As funções superiores estão intimamente relacionadas e se desenvolvem em um processo de estreita conexão.

Tais pressupostos teóricos são fundamentais para podermos compreender como se dá o desenvolvimento da vontade. Vigotski (2000) inclui a vontade no conjunto das funções psicológicas superiores e entende que essas funções foram antes interpsíquicas para depois tornarem-se intrapsíquicas; ou seja, a vontade se desenvolve socialmente, como algo presente na coletividade, para depois tornar-se internalizada pelo sujeito, constituindo-se como vontade individual.

Para esclarecermos este processo, discutiremos agora a temática da vontade a partir da conferência "O problema da vontade e seu desenvolvimento na idade infantil" (VIGOTSKI, 2001a). Nesta oportunidade Vigotski destacou que tradicionalmente, na Psicologia, o problema da vontade é explicado por duas tendências antagônicas: a teoria heterônoma e a teoria autônoma. O ponto de vista heterônomo engloba as teorias associacionistas e a reflexologia, e o autor considera importante destacar os avanços que essas teorias trouxeram. As teorias heterônomas avançam na medida em que fazem frente às teorias idealistas que creditam a vontade à "força do espírito". Apesar desta contribuição, tais teorias não conseguem explicar a liberdade que o indivíduo tem ao tomar uma decisão, que é precisamente o que distingue um ato volitivo de um ato não volitivo.

Por sua vez, os autores das teorias autônomas compreendem que, para explicarmos a vontade, devemos nos referir não ao afeto ou ao intelecto, mas à própria vontade. A vontade estaria regida por um princípio sobre-humano. Assim, a volição é explicada pela existência de uma atividade universal que atua sobre as forças humanas. Schopenhauer é um dos representantes dessas teorias autônomas. Para Vigotski (2001a, p. 442), o conceito de inconsciente geralmente remete a estas teorias:

Junto com essa interpretação da vontade penetrou na psicologia o conceito de inconsciente. Nele consiste o fato que há muito tempo tem freado o desenvolvimento adicional da vontade. [...] Quase todos os representantes da doutrina do inconsciente são, em maior ou menor grau, schopenhaueristas, quer dizer, partem de uma interpretação voluntarista da natureza da psique humana, ao que ultimamente chegam também cientistas como Freud (grifos nossos).

O que Vigotski discute é que as teorias autônomas pertencem à corrente filosófica idealista. Ele destaca duas tendências dentro dessas teorias autônomas:

[...] Em primeiro lugar, o reconhecimento da vontade como algo primário, algo que permanece fora do aspecto consciente da personalidade humana, que constitui determinada força inicial, que move em igual grau o aspecto materialista e espiritual da vida. Em segundo lugar, no outro polo se encontra a teoria dos espiritualistas, cujos representantes estão relacionados historicamente como a filosofia de Descartes e através dele com a filosofia medieval cristã. Como se sabe, a teoria cartesiana toma como fundamento o princípio espiritual, que, ao que parece, é capaz de dirigir toda a alma humana e, portanto, todo o comportamento do homem (VIGOTSKI, 2001a, p. 442-443).

Assim, dentro das teorias autônomas temos estes dois tipos de teorias, as schopenhaueristas e as cartesianas. Segundo Vigotski (2001a), para os shopenhauristas a vontade é algo a priori, que está fora da consciência e que determina o comportamento do homem. Seria um princípio sobre-humano, uma atividade universal que subordinaria o comportamento. Por sua vez, os autores espiritualistas, que se baseiam na noção cartesiana de separação entre mente e corpo, entendem que há um princípio espiritual que move o homem. Vigotski (2001a) cita Willian James como um representante desta vertente. James criou uma teoria sobre a vontade que denominou com uma palavra latina, advinda da Bíblia, pela qual Deus criou o mundo, a qual significa "haja" (com o sentido da expressão: "Que haja a luz!"). Para James, a relação existente entre os fenômenos espirituais e os fenômenos físicos é inexplicável e só pode demonstrar a existência de um fluxo de energia espiritual, que é capaz de fazer que o estímulo mais fraco seja vitorioso sobre um estímulo muito forte.

Vigotski (2001a) analisa que as teorias shopenhauristas e as baseadas nos princípios cartesianos se assemelham, pois ambas entendem que a vontade é algo primário, que se constitui como uma exceção dos demais processos da psique humana, e que não admite uma explicação causal. Para Vigotski (2001a), muitas das teorias que tradicionalmente trabalham com o conceito de inconsciente podem ser incluídas no grupo das teorias autônomas, consideradas como teorias idealistas, visto que entendem que existe algo a priori, inconsciente, que determina o comportamento humano.

A partir dessa análise sobre as teorias autônomas e das discussões realizadas sobre as filosofias idealistas, entendemos que, para Vigotski (2001a), não existe algo a priori que determine as ações humanas, como uma força oculta, seja este algo consciente ou inconsciente. As funções psicológicas superiores, entre elas a volição, são construídas socialmente nas e pelas relações sociais. Assim, concluímos que o que move o homem, o motivo de sua ação, 
é construído na sua atividade social. Nem sempre temos consciência do motivo de nossas ações, mas nem por isso esse motivo foi dado a priori. Também os motivos inconscientes são construídos nas relações sociais.

A partir dessa discussão, compreendemos que não existem conteúdos dados a priori, inconscientes "em si e por si”, que determinam o comportamento. A volição, o que move o sujeito no mundo, não é algo místico ou espiritual. A vontade é desenvolvida socialmente a partir da Lei da Internalização. Passamos a ser nós mesmos pelos outros, ou seja, o que desejamos advém da cultura, de nossa inserção social, tendo sempre em vista a forma como o universal, o particular e o singular estão imbricados.

Oliveira (2001) 1 compreende que a singularidade (o indivíduo) se constrói na universalidade (o gênero humano), ao mesmo tempo em que a universalidade se concretiza na singularidade, por meio das relações sociais específicas do contexto em que este indivíduo está inserido, relações que a autora denomina de particularidade. A universalidade é uma abstração que tem como base a realidade concreta, mas que só existe quando se concretiza no singular. Por sua vez, o singular também não pode ser compreendido em si mesmo, mas somente em sua relação intrínseca com o universal, relação que se dá através de mediações (o particular). Assim, minha forma singular de agir no mundo, meus desejos específicos estarão sempre em conformidade com as condições particulares da minha existência histórica, mas sua referência máxima é a forma universal de o homem (o gênero humano) agir no mundo. Em uma última palavra, o desejo, a vontade é, ao mesmo tempo, universal, singular e particular.

Vigotski (2004a) deixa claro que podemos agir em decorrência de motivos inconscientes. Nem sempre temos consciência do que impulsiona nossas ações, e esses motivos inconscientes geram essas ações, já que tanto os processos conscientes como os inconscientes agem sobre o comportamento do sujeito precisamente porque são processos psicofisiológicos integrais. Além disso, podemos concluir, a partir dos textos discutidos acima, que, para Vigotski (2000, 2001a), os motivos inconscientes não foram criados a priori nem vieram de um impulso espiritual do sujeito. Os motivos inconscientes são criados da mesma forma que os conscientes, ou seja, socialmente, a partir da mediação com os signos.

Com base na Psicologia Histórico-Cultural, Martins (2007) afirma que nem sempre os indivíduos têm consciência do motivo de sua atividade, ou seja, a existência de motivos e a consciência deles são fenômenos diferentes. Destaca que "os motivos não conscientes, porém, possuem a mesma determinação que qualquer outro, só podendo ser reconhecidos pela pessoa com o auxílio de sua relação com o mundo exterior" (MARTINS, 2007, p. 112). O inconsciente se radica nas relações sociais, na produção de vida material dos homens. Para a autora, deve-se tratar a questão da consciência/inconsciência das vivências partindo-se do entendimento de que a consci-

${ }^{1}$ Exposição apresentada na abertura do V Encontro de Psicologia Social Comunitária sobre o tema "O método materialista histórico-dialético", promovido pela Abrapso - Núcleo Bauru, Neppem e o Departamento de Psicologia da Faculdade de Ciências/Unesp-Bauru, nos dias 16 a 18/08/2001 ência é um continuum estruturado por relações objetivas de produção da vida material. "Como o número dessas relações é em princípio infinito, impossível se torna que tenhamos total consciência delas, ou seja, nenhuma vivência se torna absolutamente consciente em todas as suas relações objetivas" (MARTINS, 2007, p. 114). No entanto, é importante considerar que toda vivência mantém necessariamente alguma relação objetiva; portanto, não pode ser absolutamente inconsciente. A consciência de um fenômeno é a unidade que engloba aquilo que se tem consciência e os aspectos que estão inconscientes.

\section{A diferença entre os termos inconsciente e não consciente: o pensamento por conceitos a tomada de consciência}

Em Psicologia da arte, em "A psique, a consciência e o inconsciente" e em outros textos já analisados neste trabalho, Vigotski $(1972,2004 a)$ utiliza o termo "inconsciente"; já em "Pedologia da adolescência" (VIGOTSKI, 1996) e em "Pensamento e linguagem" (VIGOTSKI, 2001b), vemos uma predominância do termo "não consciente". Discorreremos a seguir sobre as considerações do autor nos últimos dois textos citados, especificamente no que diz respeito ao desenvolvimento do pensamento por conceitos e ao processo de tomada de consciência. Ao discutir estas temáticas, Vigotski (1996, 2001b) fala sobre os processos não conscientes do psiquismo.

Vigotski (2001b) analisa que, para que se possa explicar o desenvolvimento do pensamento e da linguagem, é preciso compreender que estas funções estão interligadas e considerar a relação interfuncional existente, ou seja, como estas funções se organizam em uma estrutura integral. O autor expõe que a idade de transição marca uma dupla transformação no desenvolvimento intelectual do adolescente - no conteúdo e na forma do pensamento - e marca a transição para o pensamento por conceitos. Vigotski (1996) analisa que o pensamento por conceitos é a chave de todo o desenvolvimento do pensamento nesse período. O pensamento por conceitos desempenha um papel decisivo na idade de transição, que permite ao adolescente compreender o mundo e suas próprias vivências.

O desenvolvimento do pensamento possui um significado central para o desenvolvimento de todas as demais funções psíquicas (atenção, memória, percepção, vontade), e o processo de formação de conceitos define todas as mudanças que ocorrem na psicologia do adolescente. Todas as demais funções psíquicas se intelectualizam e se reestruturam por influência do desenvolvimento do pensamento por conceitos, e é a partir deste desenvolvimento que se formam a personalidade e a concepção de mundo do adolescente (VIGOTSKI, 1996). O autor denomina esse processo de neoformação. Em cada idade se formam novas e complexas combinações entre as funções elementares, originando novas sínteses complexas a partir do desenvolvimento de uma função diretriz. $\mathrm{O}$ que se modifica não são isoladamente as funções, mas as relações entre as funções psíquicas. Vigotski (1996) sistematiza este entendimento expondo que as funções particulares se integram em uma nova síntese complexa e 
que o desenvolvimento do pensamento se constitui como a função central que impulsiona o surgimento dessas novas relações na adolescência.

É a partir do desenvolvimento do pensamento por conceitos que o adolescente conhece e sistematiza o mundo de suas próprias vivências e avança no desenvolvimento e estruturação de sua consciência. Ele vive a tomada de consciência de seus próprios processos de comportamento, os quais ele passa a dominar. As formas de conduta, que antes eram sociais e faziam parte de sua vida coletiva, agora são esferas internas da personalidade e geram uma mudança em seu comportamento.

A autoconsciência desenvolve-se a partir do pensamento por conceitos. A formação de conceitos possibilita a autopercepção, o conhecimento profundo da realidade interna, do mundo de suas próprias vivências. Assim, a autoconsciência não é algo inerente à consciência desde o início do desenvolvimento desta. O pensamento por conceitos possibilita a compreensão da realidade, dos demais e de nós mesmos.

Vigotski (1996) afirma que o pensamento por conceitos se relaciona com o desenvolvimento pleno da consciência do ser humano. É graças ao pensamento por conceito que se estrutura a autoconsciência do indivíduo. Para Vigotski, conforme Marx e Engels, a liberdade se vincula ao conhecimento da necessidade. A liberdade não consiste na independência das leis naturais, mas no conhecimento destas leis, que abre a possibilidade de fazê-las atuar de acordo com fins determinados, como já discutimos anteriormente. Isto diz respeito tanto às leis da natureza exterior quanto às leis espirituais do homem (para os autores, estas duas classes de leis podem ser separadas apenas na imaginação, mas não na realidade). Explica Vigotski (1996, p. 200):

Esta definição nos permite ver até que ponto se relaciona o livre arbítrio com o pensamento por conceitos, já que tão somente o conceito aumenta o conhecimento da realidade, faz você passar do nível das vivências para o nível de compreensão das leis. E somente esta compreensão da necessidade, quer dizer, das leis, subjaz no livre arbítrio. A necessidade se converte em liberdade através do conceito.

O ser humano possui a capacidade de não permanecer no abstrato e incompleto "em si" e de converter-se em um ser "para si". Os argumentos analisados até agora sobre o processo de formação de conceitos são importantes para podermos compreender o que Vigotski (1996) discute a respeito dos processos não conscientes. $\mathrm{O}$ autor analisa as investigações de Jean Piaget a respeito do desenvolvimento do pensamento. Para Piaget, há uma mudança radical entre o pensamento da criança e o do adolescente. Suas investigações demonstram que a criança em idade escolar não é consciente de suas próprias operações mentais e por isso não consegue dominá-las plenamente. $\mathrm{Na}$ infância há uma ausência da voluntariedade do pensamento e da tomada de consciência das próprias operações lógicas, ou seja, há uma ausência do pensamento lógico. Somente ao término da idade escolar a criança passa a ser capaz de tomar consciência de suas operações intelectuais e de compreender que as palavras são signos, e não propriedades do objeto.

Vigotski (2001b) pontua que é fundamental compreendermos por que o escolar não tem consciência de seus conceitos para podermos apreender como se dá a tomada de consciência. Sobre isso, Piaget aponta que a não consciência dos processos do pensamento, característica das crianças na idade escolar, é um resíduo de seu egocentrismo. Seria consequência residual do mundo inteiramente não conscientizado da criança e da insuficiente socialização de seu pensamento. Piaget compreende que a tomada de consciência se deve ao deslocamento dos remanescentes do egocentrismo verbal para o pensamento social maduro, num processo em que um modo de agir descola o outro.

Vigotski (2001b) destaca que a tese de Piaget sobre o porquê de os escolares não serem conscientes de seus conceitos é duvidosa, e a rejeita. Segundo ele, se discordamos da primeira tese, necessariamente iremos rejeitar também a segunda, que explica como ocorre a tomada de consciência. $\mathrm{O}$ autor entende que não é possível explicar a não consciência dos conceitos pelas crianças como decorrente de seu egocentrismo, pois nesta fase já estão em processo de desenvolvimento as funções superiores, que se caracterizam pela tomada de consciência e arbitrariedade. Por exemplo, o escolar já está desenvolvendo a atenção arbitrária e a memória lógica.

Por outro lado, Piaget tem razão quando diz que o escolar não tem consciência de seus conceitos. Para Vigotski (2001b), esta tese é correta. Neste período a criança é capaz de realizar a tomada de consciência no campo da memória, da percepção e da atenção, mesmo que ainda pautada no concreto-visual e na combinação deste com a linguagem, mas não é capaz de apreender os processos do próprio pensamento, fenômeno aparentemente paradoxal. Para explicar esse fenômeno contraditório, Vigotski (2001b, p. 209) retoma as leis do desenvolvimento psicológico; lembra-nos que o desenvolvimento psíquico é antes uma mudança nos vínculos e relações interfuncionais do que um aperfeiçoamento de determinada função, como discutimos acima:

[...] A consciência se desenvolve como um todo, modificando a cada nova etapa a sua estrutura interna e o vínculo entre as partes, e não como uma soma de mudanças parciais que ocorrem no desenvolvimento de cada função isolada. O destino de cada parte funcional no desenvolvimento da consciência depende da mudança do todo e não o contrário.

A consciência é um todo único, e suas funções particulares são interligadas. É uma unidade funcional, e há um vínculo indissolúvel entre as modalidades de sua atividade. Os vínculos e as relações funcionais não são constantes ao longo do desenvolvimento do sujeito: “[...] a mudança das conexões interfuncionais, quer dizer, as mudanças da estrutura funcional da consciência é o que constitui o aspecto central de todo o processo de desenvolvimento psicológico" (VIGOTSKI, 2001b, p. 210211, grifos do autor). 
Para Vigotski (2001b), este entendimento de que no processo de desenvolvimento do sujeito modifica-se a estrutura da consciência, ou seja, ocorre uma mudança nos vínculos e relações interfuncionais, é fundamental para compreendermos por que, na idade escolar, a memória e a atenção são conscientizadas e arbitrárias, em um determinado grau ou qualidade, e os próprios processos do pensamento ainda não o são. A tomada de consciência é um processo superior em qualquer função, e surge tardiamente, devendo ser necessariamente precedida por um estágio de funcionamento não consciente e involuntário, não arbitrário, daquela função, daquele tipo de atividade da consciência. "[...] Para tomar consciência é necessário haver o que deve ser conscientizado. Para dominar, é necessário dispor daquilo que deve ser subordinado à nossa vontade" (VIGOTSKI, 2001b, p. 211).

Na infância, a percepção e a memória são as funções que dominam o sistema de relações interfuncionais. Assim, ao chegar ao limiar da idade escolar a criança já possui estas funções bem desenvolvidas. Ela já possui aquilo de que deve se conscientizar e assimilar. É por isso que neste período as funções conscientizadas da memória e da atenção são projetadas ao centro. A aprendizagem está sempre adiante do desenvolvimento, o que significa que a criança adquire certos hábitos e habilidades específicas antes de aprender a aplicar estas habilidades de forma consciente e intencional (VIGOTSKI, 2001b).

Vigotski (2001b) afirma que no fundamento da tomada de consciência está a generalização dos próprios processos psíquicos, e isto conduz ao domínio voluntário de cada função psíquica. É no campo dos conceitos científicos que a tomada de consciência surge primeiro. Os conceitos científicos constituem um sistema hierárquico interno de relações mútuas, e é neles que surge pela primeira vez um sistema de generalização e domínio. Sendo assim, os conceitos científicos pressupõem a tomada de consciência, e é somente dentro de um sistema que um conceito adquire caráter voluntário e consciente; ou seja, a tomada de consciência pressupõe sistematização dos conceitos. Os conceitos infantis são espontâneos, não sistemáticos - portanto, não conscientes. Para Vigotski, uma vez que a estrutura de generalização surge em uma esfera do pensamento por conceitos, ela se transfere para as demais. "[...] Deste modo, a tomada de consciência vem pela porta dos conceitos cientificos" (VIGOTSKI, 2001b, p. 214, grifos do autor), entendendo-se que a formação de conceitos científicos é o processo de formação do pensamento teórico.

Os conceitos científicos são conscientes desde o primeiro momento e dispõem desde o início de um sistema. É a organização em um sistema que diferencia os conceitos científicos dos conceitos espontâneos. Para Vigotski (2001b), dizer que um conceito é espontâneo e não consciente é o mesmo que dizer que o conceito carece de um sistema de enlaces conceituais. O caráter não consciente significa que falta a generalização, o desenvolvimento do sistema de relação entre os diversos conceitos. Por outro lado, Vigotski (1996) destaca que os conceitos científicos estão estritamente relacionados com os conceitos espon- tâneos. É preciso que a criança tenha desenvolvido seus conceitos cotidianos para que ela possa assimilar e tomar consciência dos conceitos científicos. O autor exemplifica apontando que, para a criança compreender o conceito científico de "história", é necessário que ela tenha desenvolvido o conceito espontâneo de "passado", que ela e as pessoas à sua volta já tenham vivido o suficiente para perceberem que existe um "antes" e um "agora".

E é em meio a essa discussão sobre a tomada de consciência que Vigotski (2001b) traz o que considera ser a diferença essencial entre os processos inconscientes e os não conscientes. Pedimos licença ao leitor para reproduzirmos na íntegra o trecho no qual o autor discute essa diferença:

[...] Quando Piaget se refere ao caráter não-consciente do pensamento infantil, não leva em consideração que a criança não é consciente do que ocorre em sua consciência, que seu pensamento é inconsciente. Supõe que a consciência participa do pensamento da criança, mas não até o final. A princípio, o pensamento inconsciente - o solipsismo da criança, ao final, o pensamento socializado consciente, no meio, uma série de etapas, caracterizadas por Piaget como a diminuição gradual do egocentrismo e o incremento das formas sociais de pensamento. [...] O que significa que o pensamento da criança não é consciente? Significa que o egocentrismo desta última implica certa inconsciência, o que por sua vez significa que o pensamento é consciente, mas não até o final, que encerra elementos conscientes e não conscientes. [...] Se se considera o desenvolvimento da consciência como a transição paulatina do inconsciente (no sentido freudiano) a consciência total, este raciocínio é correto. Porém, como resultado das investigações de Freud foi estabelecido que o inconsciente como algo reprimido da consciência surge tarde e é, em certo sentido, uma grandeza derivada do desenvolvimento e da diferenciação da consciência. Por isso existe uma grande diferença entre o inconsciente e o não consciente. A não-consciência não é, de modo algum, uma parte do inconsciente, nem uma parte da consciência. Não significa um grau de consciência, mas sim uma tendência diferente da atividade da consciência. Dou um nó. $\mathrm{O}$ faço conscientemente. Contudo, não consigo explicar como o fiz. Resulta que não tenho consciência do meu ato consciente, porque minha atenção está orientada para o ato da própria execução e não para como eu faço. A consciência é sempre um determinado fragmento da realidade. O objeto de minha consciência é o ato de dar o nó, o próprio nó e tudo que acontece com ele, porém não consiste nas ações que realizo ao fazê-lo nem em como eu faço. Mas o objeto da consciência pode ser precisamente isso, em cujo caso se tratará da tomada de consciência. A tomada de consciência é um ato da consciência, o objeto da qual é a própria atividade da consciência (VIGOTSKI, 2001b, p. 212-213, grifos nossos).

Em nossa análise, o que Vigotski discute é que, quando Piaget fala do caráter não consciente do pensamento da criança e o chama de pensamento inconsciente, ele não compreende que o pensamento é absolutamente inconsciente, mas sim que a consciência da criança participa do pensamento, embora não até o final; ou seja, a

Fractal, Rev. Psicol., v. 33 - n. 2, p. 62-71, 2021 
criança pensa, tem consciência "do que" está pensando, mas não tem consciência de "como" está pensando; seu "processo" de pensamento não está conscientizado.

Para Piaget, o pensamento da criança pequena seria egocêntrico (centrado em suas experiências pessoais) e inconsciente, enquanto o pensamento do adulto seria socializado e consciente. Vigotski critica este entendimento, apontando que ele provém da lógica formal. Para o autor russo, o pensamento socializado não é sempre consciente, e o pensamento egocêntrico não é necessariamente inconsciente. $\mathrm{O}$ egocentrismo infantil implica certa inconsciência, o que não quer dizer total falta de consciência. Por isso o próprio Piaget aponta que o termo "raciocínios inconscientes" é escorregadio, pois se a criança raciocina, se ela pensa, como este pensamento não faria parte de sua consciência? Na verdade, a criança tem consciência do "objeto" de seu pensamento, mas não do "processo" pelo qual ela pensa.

Para Vigotski, existe uma grande diferença entre o "inconsciente" e o "não consciente". O não consciente não é uma parte do inconsciente ou uma parte da consciência, não é um grau de consciência. Os conteúdos não conscientizados são, na verdade, uma tendência da atividade da consciência. Quando o sujeito dá um nó, ele tem consciência do que está fazendo. Ele define, consciente e intencionalmente, que irá dar um nó; mas, ao dar o nó, o sujeito focaliza sua consciência "no que" está fazendo, e não em "como" está fazendo. Não volta sua atenção para cada detalhe do movimento e por isso não toma consciência de cada ato; mas o sujeito pode tornar este "como" o objeto de sua atenção, ou seja, pode focalizar a sua atenção no "processo" pelo qual pensa ou age, pode "transferir" sua atividade consciente para o processo - caso em que se terá a tomada de consciência. Esta ocorre quando o objeto do pensamento é a própria atividade da consciência.

Em nossa análise, o que Vigotski (2001b) discute é que existe uma diferença metodológica entre utilizar o termo "inconsciente" e o termo "não consciente". Este refere-se a uma tendência diferente da atividade da própria consciência; aquele remete ao que tradicionalmente a psicanálise compreende sobre o conceito de inconsciente, ou seja, que este é uma instância psíquica separada da consciência, um termo que denomina os processos que estão fora da consciência.

Vigotski (2001b) conclui que a consciência é um todo único, um sistema psicológico composto pelo conjunto das funções psíquicas superiores, que estão imbricadas umas nas outras. Assim, como poderia haver processos psíquicos que estejam absolutamente fora da consciência?

Vigotski (1972, 2004a) discorda da explicação dada por Freud ao conceito de inconsciente, que define que os processos inconscientes estão apartados da consciência. Em nossa análise, o que Vigotski (2001b) está discutindo é que o que existe empiricamente são os processos "não conscientes" do pensamento, e que os processos tradicionalmente denominados pelo termo "inconsciente" são, na verdade, uma tentativa teórica de explicar os fenômenos não conscientes, o que acaba por confundir o material sensível com as hipóteses de explicação do fato, como ele discute em "A psique, a consciência e o inconsciente" (VIGOTSKI, 2004a). Diante dessas considerações, concluímos que Vigotski opta por utilizar o termo "não consciente" a partir de um novo entendimento teórico dos processos psíquicos tradicionalmente denominados de "inconscientes".

Sendo assim, compreendemos que, em "Pedologia do adolescente" (VIGOTSKI, 1996) e em "Pensamento e linguagem" (2001b), o autor traz considerações fundamentais, que nos permitem pensar sobre a consciência/não consciência dos fenômenos. Desta discussão podemos concluir que é a partir do desenvolvimento do pensamento por conceitos e da tomada de consciência dos seus próprios processos de pensamento que o adolescente regula o mundo de suas próprias vivências e toma consciência delas, desenvolvendo assim sua autoconsciência. Isto significa que o pensamento não consciente é caracterizado pela falta dessa autoconsciência das próprias vivências.

Os conceitos do escolar não são conscientes nem voluntários, ou seja, o pensamento não consciente é involuntário e não está sob o seu domínio pleno. O pensamento não consciente não é livre, já que a necessidade pode se converter em liberdade por meio do conceito. Sendo assim, é somente através do pensamento por conceitos e do desenvolvimento da autoconsciência que o sujeito desenvolve o controle voluntário do comportamento e o livre arbítrio; a partir deste processo ele pode tomar consciência de suas próprias ações, dos seus motivos.

Para Vigotski (1996), nós nos comportamos em relação a nós mesmos do mesmo modo que o fazemos em relação aos demais. Nossa visão de mundo está estreitamente relacionada com a forma como a sociedade compreende o mundo, produz e reproduz a vida material; "mas a subordinação das próprias ações ao próprio poder exige necessariamente, como premissa, a tomada de consciência destas ações" (VIGOTSKI, 1996, p. 230); ou seja, é necessário que tomemos consciência de nosso próprio pensamento, de nossos motivos, de nossas ações, de nossa história pessoal e social, para podermos decidir mais livremente o curso que desejamos imprimir às nossas vidas e à sociedade como um todo.

\section{Considerações finais}

A partir dos estudos de Vigotski, pudemos concluir que é importante tornar consciente os conteúdos não conscientes, porque o livre-arbítrio está relacionado com a capacidade de tomar decisões com conhecimento. $\mathrm{O}$ conceito de liberdade se vincula ao conhecimento do motivo que impulsiona as ações, seja ele consciente ou não consciente. É necessário que o homem tome consciência de seu próprio pensamento, de seus motivos, de suas ações, de sua história pessoal e social, para que possa decidir mais livremente, no interior das condições concretas, o curso que deseja imprimir à sua vida e à sociedade como um todo. É imprescindível que o homem submeta as relações sociais objetivadas ao controle coletivo consciente, para que os indivíduos possam se desenvolver como individualidade livre e universal. 
O processo de conscientização está intimamente relacionado ao processo pelo qual a criança se apropria das significações sociais, em forma de conceitos. Conforme o sujeito se apropria das significações sociais, desenvolvendo os conceitos espontâneos e posteriormente os conceitos científicos, ele altera sua consciência sobre o mundo circundante e sobre as relações sociais nas quais está inserido. Sua atividade social provoca em sua consciência mudanças que, por sua vez, provocam mudanças em sua atividade social. O desenvolvimento do pensamento por conceitos possibilita ao sujeito compreender a realidade e a si mesmo e desenvolver sua autoconsciência.

A conscientização dos motivos em forma de ideias ou conceitos só se dá a partir da relação do sujeito com o mundo exterior, de um processo de ação e reflexão do indivíduo sobre seu mundo interno que ocorre a partir do sistema de significações e conceitos apreendidos por ele. As emoções auxiliam neste processo, porque se constituem como sinais internos, refletem as relações entre a atividade e o motivo, e possibilitam que o sujeito conheça o motivo e o sentido pessoal de sua atividade. A tomada de consciência dos motivos da atividade requer que o homem compreenda e se conscientize dos conceitos e significados de que vai se apropriando e objetive-se como um ser coletivo e social, como ser genérico.

Esperamos que nosso estudo tenha suscitado muitos questionamentos ao leitor e que impulsione novas pesquisas a respeito dos processos psíquicos conscientes e não conscientes e sobre a atuação do psicólogo clínico, a partir da Psicologia Histórico-Cultural. Entendemos que a prática clínica nesta perspectiva pode retroalimentar dialeticamente a teoria, impulsionando-a para a elaboração de um arcabouço teórico-prático neste campo de atuação.

\section{Informações sobre as autoras:}

\section{Elis Bertozzi Aita \\ (iD) https://orcid.org/0000-0001-8197-2271 \\ (9) http://lattes.cnpq.br/6425410273283098}

Doutora em Psicologia pelo Programa de Pós-graduação em Psicologia da Universidade Estadual de Maringá (UEM), na linha de Desenvolvimento Humano e Processos Educativos. Mestre em Psicologia (UEM). Atua como psicóloga clínica a partir da Psicologia Histórico-Cultural.

\section{Silvana Calvo Tuleski \\ (iD) https://orcid.org/0000-0002-6967-2548 \\ (9) http://lattes.cnpq.br/0105108434995580}

Psicóloga, com formação acadêmica e atuação profissional na área de Psicologia Escolar e Educacional. É especialista em Psicologia da Educação, mestre em Educação pela Universidade Estadual de Maringá/PR, doutora e pós-doutora em Educação Escolar pela UNESP - Campus de Araraquara/SP. É professora Associada do Departamento de Psicologia da Universidade Estadual de Maringá/ PR. Participa dos Diretórios de Pesquisa/CNPq intitulados: Estudos Marxistas em Educação, Psicologia Histórico-Cultural e Educação e do Grupo de Estudos e Pesquisas em Educação Infantil. Coordenadora do LAPSIHC (Laboratório de Psicologia Histórico Cultural) da Universidade Estadual de Maringá.

\section{Contribuição das autoras:}

As autoras colaboraram ao longo do processo, desde a elaboração até a revisão final do manuscrito. Ambas aprovaram o manuscrito final para publicação.

\section{Como citar este artigo:}

\section{ABNT}

AITA, Elis Bertozzi; TULESKI, Silvana Calvo. O conceito de inconsciente para Vigotski: primeiras aproximações. Fractal: Revista de Psicologia, Niterói, v. 33, n. 2, p. 62-71, maio/ago. 2021. https://doi.org/10.22409/1984-0292/v33i2/5863

\section{APA}

Aita, E. B.; Tuleski, S. C. (2021, Maio/Agosto). O conceito de inconsciente para Vigotski: primeiras aproximações. Fractal: Revista de Psicologia, 33(2), 62-71. doi: https://doi. org/10.22409/1984-0292/v33i2/5863

\section{Copyright:}

Copyright (C) 2021 Aita, E. B.; Tuleski, S. C. Este é um artigo em acesso aberto distribuído nos termos da Licença Creative Commons Atribuição que permite o uso irrestrito, a distribuição e reprodução em qualquer meio desde que o artigo original seja devidamente citado.

Copyright (C) 2021 Aita, E. B.; Tuleski, S. C. This is an Open Access article distributed under the terms of the Creative Commons Attribution License, which permits unrestricted use, distribution, and reproduction in any medium, provided the original article is properly cited.

\section{Referências}

MARTINS, Lígia Márcia. A formação social da personalidade do professor: um enfoque vigotskiano. Campinas: Autores Associados, 2007.

OLIVEIRA, Betty. A dialética do singular-particularuniversal. In: ENCONTRO DE PSICOLOGIA SOCIAL COMUNITÁRIA, 5, 2001, Bauru. Anais... Bauru: UNESP, 2001. Disponível em: http://evoluireducacional.com.br/wpcontent/uploads/2012/08/OLIVEIRA-B.-A-Dialetica-doSingular-Particular-Universal.pdf. Acesso em: 22 abr. 2017.

SANTOS, Lívia Gomes dos; LEÃO, Inara Barbosa. O inconsciente sócio-histórico: notas sobre uma abordagem dialética da relação consciente-inconsciente. Psicologia \& Sociedade, v. 24, n. 3, p. 638-647, 2012. Disponível em: https:// www.scielo.br/pdf/psoc/v24n3/17.pdf. Acesso em: 12 mar. 2017.

SANTOS, Lívia Gomes dos; LEÃO, Inara Barbosa. O inconsciente sócio-histórico: aproximações de um conceito. Psicologia \& Sociedade, v. 26 (n. spe. 2), p. 38-47, 2014. https://doi.org/10.1590/S0102-71822014000600005

SILVA, Maria Aparecida Santiago da. Compreensão do adoecimento psíquico: de L. S. Vigotski à Patopsicologia Experimental de Bluma V. Zeigarnik. 2014. 256 f. Dissertação (Mestrado)-Programa de Pós-Graduação em Psicologia da Universidade Estadual de Maringá, Paraná, PR, 2014. Disponível em: http://repositorio.uem.br:8080/jspui/ handle/1/3026. Acesso em: 18 mar. 2017.

TOASSA, Gisele. Emoções e vivências em Vigotski: investigação para uma perspectiva históricocultural. 2009. 348 f. Tese (Doutorado)-Instituto de Psicologia da Universidade de São Paulo, São Paulo, 2009. https://doi.org/10.11606/T.47.2009. tde-19032009-100357 
VIGOTSKI, Lev Semionovitch. Psicología del arte. Tradução de Victoriano Imbert. Barcelona: Barral, 1972.

VIGOTSKI, Lev Semionovitch. Paidología del adolescente. In: . Obras escogidas. Tradução de Lydia Kuper. Madri:

Visor, 1996. v. 4, p. 4-200.

VIGOTSKI, Lev Semionovitch. Historia del desarrollo de las funciones psíquicas superiores. In: Obras escogidas. Tradução de Lydia Kuper. 2. ed. Madri: Visor, 2000. v. 3, p. 11-347.

VIGOTSKI, Lev Semionovitch. El problema de la voluntad y su desarrollo en la edad infantil. In: Obras Escogidas. Tradução de José Maria Bravo. 2. ed. Madri: A. Machado Libros, 2001a. v. 2, p. 439-448.

VIGOTSKI, Lev Semionovitch. Pensamento e linguagem. In: . Obras escogidas. Tradução de José Maria Bravo. 2. ed. Madrid: A. Machado Libros, 2001b. v. 2, p. 1-291.

VIGOTSKI, Lev Semionovitch. A psique, a consciência e o inconsciente. In: . Teoria e método em psicologia. Tradução de Claudia Berliner. 3. ed. São Paulo: Martins Fontes, 2004a. p. 137-159.

VIGOTSKI, Lev Semionovitch. O significado histórico da crise da psicologia. In: Teoria e método em psicologia. Tradução de Claudia Berliner. 3. ed. São Paulo: Martins Fontes, 2004b. p. 203-417. 